This item was submitted to Loughborough's Research Repository by the author.

Items in Figshare are protected by copyright, with all rights reserved, unless otherwise indicated.

\title{
Microwave assisted large scale sintering of multilayer electroceramic devices
}

PLEASE CITE THE PUBLISHED VERSION

PUBLISHER

Wiley / @ American Ceramic Society (ACerS)

VERSION

AM (Accepted Manuscript)

LICENCE

CC BY-NC-ND 4.0

\section{REPOSITORY RECORD}

Vaidhyanathan, Bala, Ketharam Annapoorani, J.G.P. Binner, and R. Raghavendra. 2009. "Microwave Assisted Large Scale Sintering of Multilayer Electroceramic Devices”. figshare. https://hdl.handle.net/2134/5600. 
This item was submitted to Loughborough's Institutional Repository (https://dspace.lboro.ac.uk/) by the author and is made available under the following Creative Commons Licence conditions.

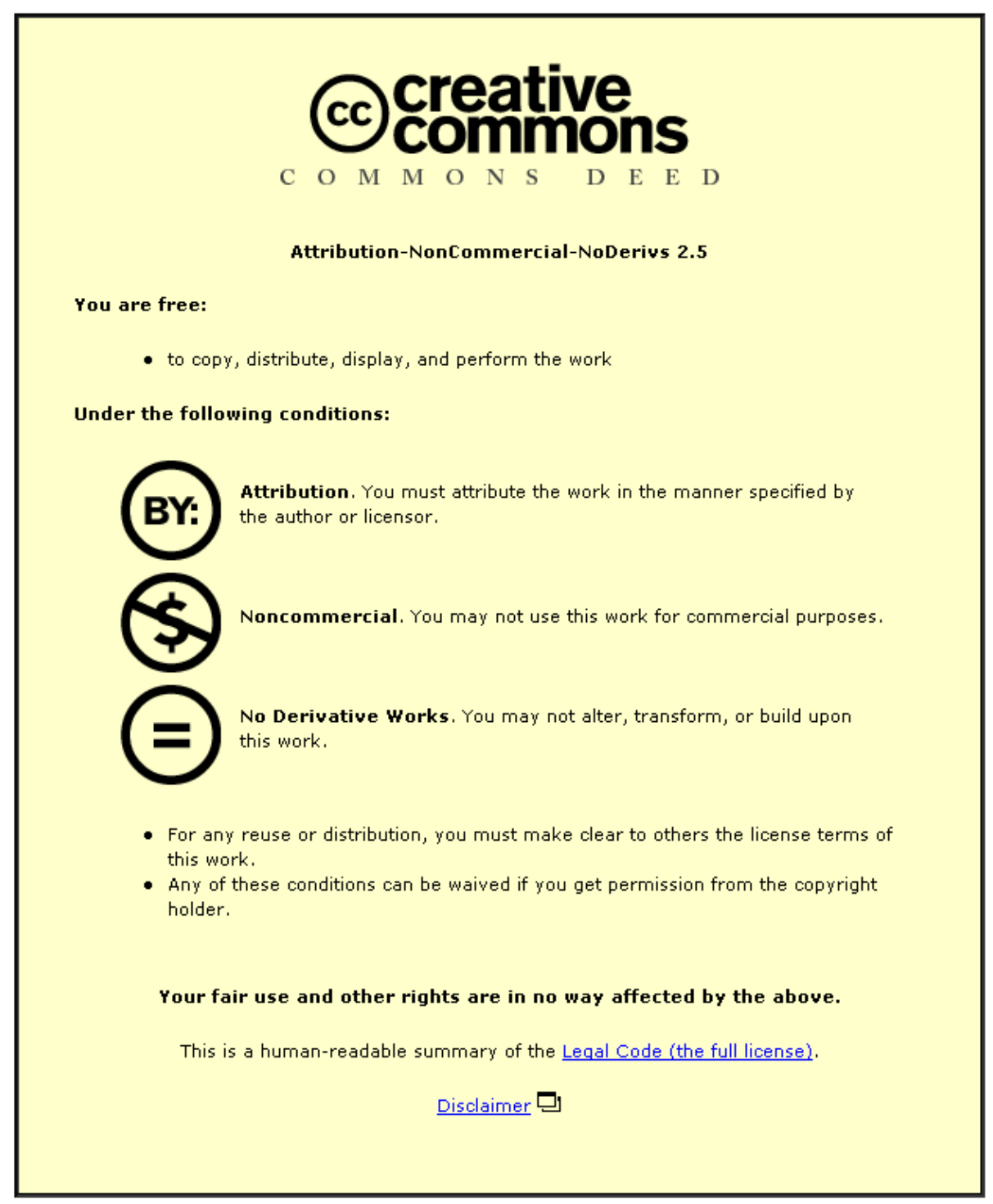

For the full text of this licence, please go to: http://creativecommons.org/licenses/by-nc-nd/2.5/ 


\title{
MICROWAVE ASSISTED LARGE SCALE SINTERING OF MULTILAYER ELECTROCERAMIC DEVICES
}

\author{
B.Vaidhyanathan ${ }^{1,}$, ${ }^{*}$ K.Annapoorani ${ }^{1}$, J.G.P.Binner ${ }^{1}$ and R.Raghavendra ${ }^{2}$ \\ ${ }^{1}$ Department of Materials, Loughborough University, Leicestershire, LE11 3TU, UK \\ ${ }^{2}$ Littelfuse Ireland Ltd, Dundalk, Ireland
}

\begin{abstract}
The feasibility of employing the microwave methodology for the processing of integrated passive devices (IPDs), nanocrystalline $\mathrm{ZnO}$ radials and nano multilayer varistor (MLVs) devices was explored. Methodical microwave sintering experiments were carried out using a multimode, $2.45 \mathrm{GHz}$ microwave applicator. Effect of various experimental parameters such as heating rate, cooling rate, soaking time, sintering temperature etc. on the processing of these device components was investigated in detail. The resultant products were characterized for microstructure, composition and electrical performance. The various stages involved in taking the laboratory research to industrial scale-up production were also examined. The use of microwaves for the processing of MLVs was found to genuinely improve the electrical properties in both small scale ( 200 devices/ batch) and large scale ( $\sim 2000$ devices/batch) sintering situations. For a stand alone microwave heating process a back-toback cascading /conveyer belt arrangement is recommended for continuous large scale production. However hybrid heating methodology was found to provide the capability of stacking operations and could be helpful in avoiding the use of 'casketing', besides providing the possibility of achieving uniform temperature across a large volume. The technique seems to be attractive in terms of its simplicity, rapidity, economic viability and the superior product performance achieved in all the cases augers well for its general applicability.
\end{abstract}


Ceramics Engineering and Science Proceedings, V30 (8), p11-18, (2009).

\section{INTRODUCTION}

Electroceramic devices such as varistors, capacitors, transducers and integrated devices constitute a multibillion-dollar global market owing to their applications in most modern electronic appliances. Each of these devices consists of a dielectric layer sandwiched between metal electrodes. The key step that determines the electrical properties of such a device is sintering, which converts the green component into a dense monolithic device. The conventional manufacturing procedures available for the fabrication of these devices involve tedious multi-step binder removal stages, long processing durations and high sintering temperatures. These cumbersome procedures lead to low equipment productivity, unwanted diffusion of electrode (eg., in most multilayer structures) into the ceramic, excessive grain growth (in the case of nanocrystalline varistors), ceramic inter-diffusion at the component interface (in the case of integrated devices) and in turn inferior electrical performance. This necessitates the need to look for alternate and improved processing methodologies. It has been demonstrated by us and research laboratories around the globe that microwave heating is a viable method for the laboratory scale processing of electroceramic devices such as varistors, capacitors, integrated devices etc, owing to the associated advantages viz., savings in time and energy, improved properties and retaining of finer microstructures. ${ }^{1-7}$ However the commercial application of microwaves in high temperature sintering processes for advanced ceramics has been slow especially considering these tremendous opportunities. ${ }^{8,9}$ The barriers to commercialisation have included lack of microwave furnace suppliers, lack of understanding of the material-microwave interactions, the need for quick, convincing proof of concept studies prior to investment in equipment and the need for reproducible and scale-up process development. The present work describes the salient results obtained on the use of microwaves for the processing of some of the electroceramic devices and we envisaged that the inherent advantages of rapidity, inside-out heating and faster sintering kinetics can be exploited to circumvent some of the processing problems normally encountered during multilayer device manufacture.

\section{EXPERIMENTAL}

The microwave cavity used is capable of providing a maximum output power of $6 \mathrm{~kW}$ and operating at $2.45 \mathrm{GHz}^{10}$. The microwaves from the magnetron were transmitted through a waveguide system and launched into the cavity after reflecting onto a mode stirrer rotating at $70 \mathrm{rpm}$. The cavity was provided with a water-cooled base plate to hold the samples and an outer cooling jacket for safety. A reflected power monitoring unit and a three-stub tuner helped to tune the microwave system with minimum reflected power. Platinum sheathed, shielded R-type thermocouple and an infrared pyrometer (LAND instruments, UK) were used for temperature measurements ${ }^{11,4,5}$. Fiberfrax high purity insulation was used as a casket for heat containment. In the second part of the work, we have investigated the potential for using hybrid heating for the scale up sintering of MLVs so as to avoid the requirement of using a casket system (thereby avoiding the handling problems in industrial production units) and b) to optimise the amount of microwave power required to achieve the desired property improvements. The hybrid sintering cavity used is described elsewhere ${ }^{12}$. It also operates at $2.45 \mathrm{GHz}$ frequency and is capable of providing a maximum microwave output power of $1100 \mathrm{~W}$ and a conventional power of $5000 \mathrm{~W}$. Comparative conventional heating experiments were also performed using an electric furnace. Density measurements were performed on sintered samples using the Archimedes method using deionised water. The samples were investigated using optical microscopy (Olympus Microscopes, Japan) for electrode delamination and interface cracking. Scanning electron microscopic measurements were carried out using SEM; Leica Cambridge Stereoscan S360 and the extent of diffusion of matrix components studied using energy dispersive X-ray analysis (EDX). The electrical properties of the microwave sintered MLV samples were measured at Littlefuse Ireland Ltd. 
I-V characteristics from $0.1 \mu \mathrm{A}$ to $0.01 \mathrm{~A}$ was measured using a Keithley instrument (Model 2410, USA) and from 0.1A to 100A was measured by using a Keytek Model 711, USA surge generator. Around 100 representative samples for each experimental condition were examined for electrical performance. The electrical results were used as a pointer for optimising the experimental parameters of the subsequent microwave assisted sintering trials.

\section{RESULTS AND DISCUSSION}

\section{Microwave Processing of Integrated Passive devices}

In the modern electronic industry, the drive for component counts reduction per board and miniaturization of electronic circuits made the use of integrated components a necessity. The integration of multiple passive components into a single integrated passive device (IPD) offers significant benefits in terms of space reduction and assembly cost. However inter-diffusion of matrix components at the ceramic interface is the problem of great concern during the conventional firing of these devices. In the present case, IPD samples with a capacitor/varistor formulation were considered for investigation. The capacitor formulation is bismuth niobate doped with magnesium oxide and the varistor formulation consists of $98 \%$ of zinc oxide and $2 \%$ addition of antimony oxide, bismuth oxide, cobalt oxide, etc. Microwave sintering experiments were performed between $950^{\circ}-1100^{\circ} \mathrm{C}$ and the soaking time varied between 20-60 minutes. From Figure 1, it is clear that at any given temperature the

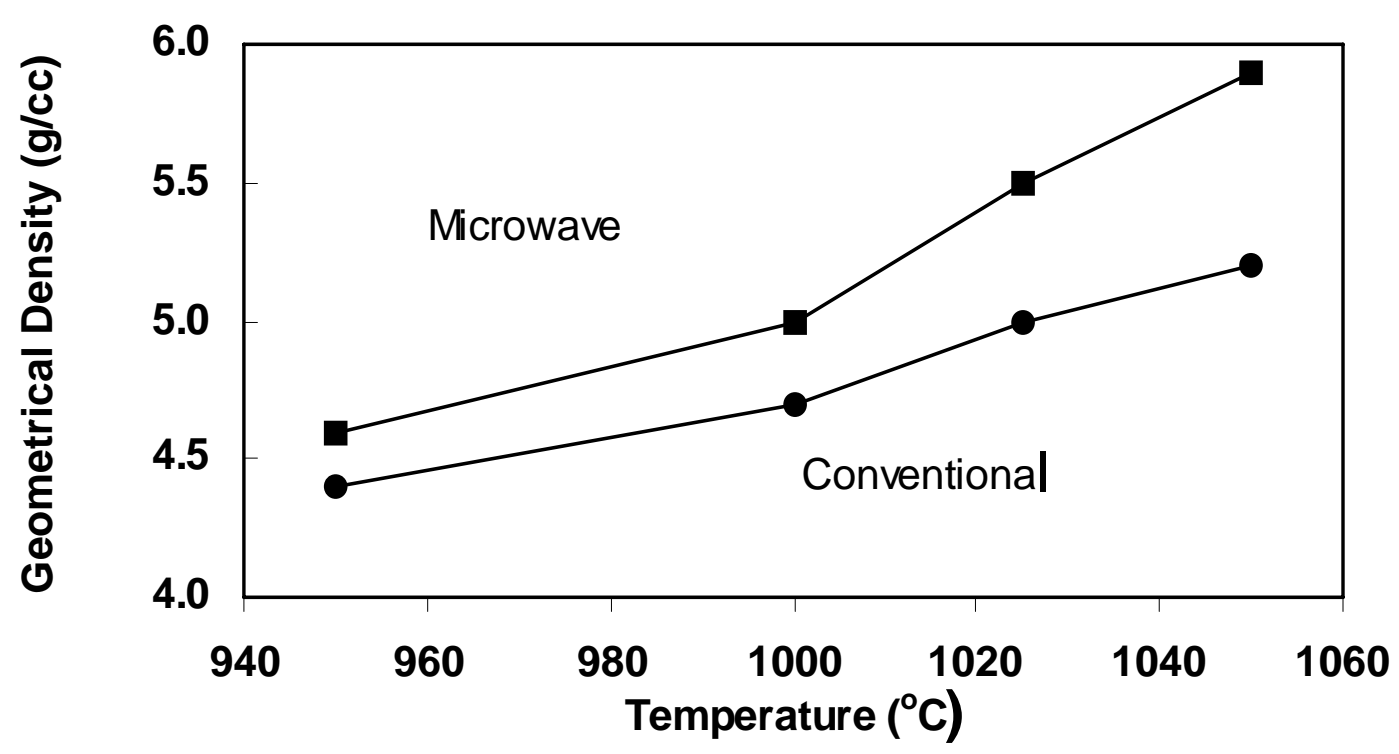

Figure 1: Densification of IPDs in microwave and conventional sintering

microwave process provides much higher densification than conventional sintering and at higher temperatures $\left(>1050^{\circ} \mathrm{C}\right)$, the capacitor region sintered more than the varistor part, leading to nonuniform shrinkage and device de-lamination.

The microwave sintered samples were further characterised using EDX and from figure 2 showing the $\mathrm{Nb}$ line analysis, it is clear that there is no diffusion of $\mathrm{Nb}$ at the ceramic interface (which is the major problem during the long duration conventional processing). Since the Nb lines overlap with that of the electrode material, sharp peaks are seen at the electrode positions (the sharpness of 
these peaks indicate the well-preserved nature of the electrodes). In contrast, it was observed that in the case of conventionally co-fired composite MLCC's there is an appreciable amount of electrode material migration into the ceramic layers ${ }^{13}$. In this context, the microwave sintering appears to be very attractive since it not only minimises the inter-diffusion of ceramic components but also reduces the electrode migration. Importantly using microwaves, IPDs could be sintered to more than $98 \%$ densification within 3 hours of total cycle time, which is one tenth of the time required by conventional methods $^{14}$.

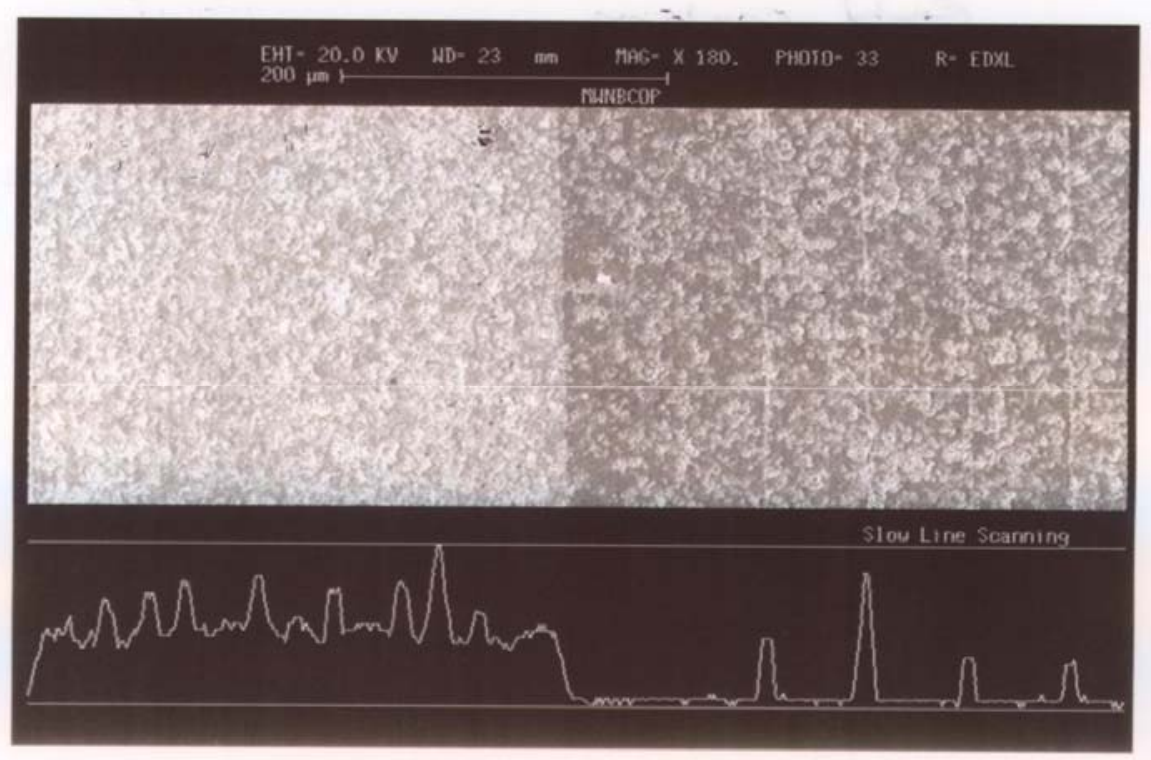

Figure 2: Line analysis of $\mathrm{Nb}$ on the sample sintered at $1050^{\circ} \mathrm{C} / 45 \mathrm{mins}$

Table I. Electrical characteristic ${ }^{* *}$ of microwave sintered IPDs

\begin{tabular}{|l|l|l|l|l|}
\hline Sintering condition & Vnom & Variance & Clamp Ratio & $\begin{array}{l}\text { Leakage } \\
\text { current }\end{array}$ \\
\hline $1050^{\circ} \mathrm{C} / 30$ mins & 45.23 & 6.93 & 1.290 & 0.927 \\
\hline $1050^{\circ} \mathrm{C} / 45$ mins & 38.53 & 6.60 & 1.343 & 0.925 \\
\hline $\begin{array}{l}1050^{\circ} \mathrm{C} / 30 \text { mins } \\
\text { flowing air } \\
\text { better casket })\end{array}$ & 43.57 & 3.93 & 1.323 & 0.930 \\
\hline Required values & $>25$ & $\sim 3.5$ & $<1.5$ & $>0.8$ \\
\hline
\end{tabular}

Table I provide the electrical performance of microwave sintered IPDs at $1050^{\circ} \mathrm{C}$ with various soaking times. It is clear that the electrical performance of the microwave sintered IPDs were found to match, and in most cases better, the required values. However initially the parameter 'Variance', was found to be higher, was circumvented by adopting a better casket design for heat containment and passing a burst of air to achieve thermal equilibrium during the microwave processing of these multilayer devices. Use of secondary susceptors was also found to be beneficial. 
2. Microwave processing of Nanocrystalline Varistor Devices

In this case, the major objective is to reduce the processing temperature (so that high $\mathrm{Ag}$ containing electrodes can be used) of the varistor devices by using the combination of nanocrystalline formulations and microwave methodology. Initial microwave sintering experiments were performed on nano varistor radials. Commercial varistor samples were also microwave sintered for comparison. Figure 3 shows the electrical characteristics of the microwave sintered varistors (at $1100^{\circ} \mathrm{C} / 15$ mins) and it is evident that the nano sample exhibits excellent electrical performance, with the nominal voltage (Vnom) increased significantly (from $650 \mathrm{~V}$ to $>1100 \mathrm{~V}$ at $1 \mathrm{~mA}$ current; the actual value is higher than this but due to equipment limitation we couldn't measure larger values - see the flatness of the voltage due to equipment saturation. Therefore another equipment is used for measurements involving currents higher than $1 \mathrm{~mA}$ ). To reduce the processing temperature, radials made from another varistor formulation (obtained from Shanxi Corporation, China) were investigated. Using a novel microwave assisted two stage sintering methodology ${ }^{12}$ (where in the difference in kinetics between the grain boundary diffusion and grain boundary migration is exploited ${ }^{15}$ to minimise the grain growth whilst achieving the required densification) nano varistor devices have been sintered at temperatures lower than $1000^{\circ} \mathrm{C}$.

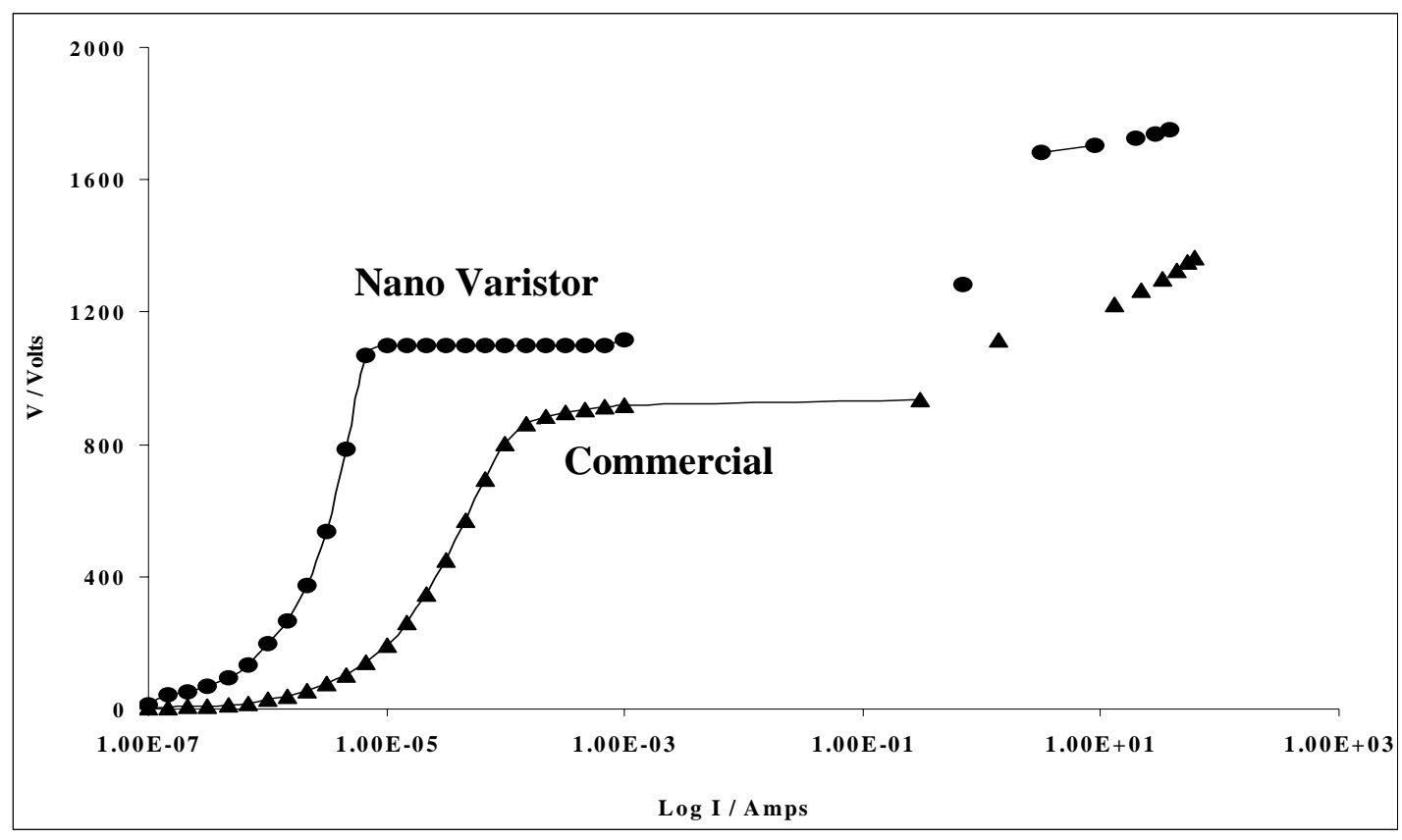

Figure 3: Electrical characteristics of the microwave sintered nano and commercial varistor samples

Multilayer structures based on nano varistor formulation were fabricated with $\mathrm{Ag}$ and $\mathrm{Ag} / \mathrm{Pd}$ electrodes and were microwave sintered successfully to more than $98 \%$ densification at temperatures lower than $950^{\circ} \mathrm{C}$. The electrical performance of these devices were found to be superior to that of micron sized commercial counter parts and the characteristics were on par with expensive Pt electroded devices $^{16,17}$. 


\section{Scale-up production of Multilayer devices}

Successful scale-up sintering of multilayer varistors (MLVs) was carried out by employing both standalone microwave and hybrid heating techniques. When we used a single sagger and $~ 2000-4000$ MLV devices in a larger $6 \mathrm{~kW}$ microwave cavity for the initial scale up sintering experiments it was found that at heating rates $>25^{\circ} \mathrm{C} / \mathrm{mins}$, the large, dense $\mathrm{ZnO}$ liners commonly used in industrial practice to hold the dielectric samples were found to crack. However by performing a number of methodical experimental trials, this was found to be avoided by employing optimum sintering schedules viz., heating time: 90-100 minutes; soaking time: 20-30 minutes; cooling was achieved by simply switching-off the magnetron and the total cycle time was between 150-180 minutes ${ }^{18}$. All the samples sintered well to obtain $>99 \%$ densification. In contrast, the conventional sintering schedule using an electric furnace involves a $3 \mathrm{~h}$ soak at $350^{\circ} \mathrm{C}$ and $2 \mathrm{~h}$ soak at $550^{\circ} \mathrm{C}$ for complete binder removal and a $12 \mathrm{~h}$ soaking time at the sintering temperature of $1200^{\circ} \mathrm{C}$ resulting in a $30 \mathrm{~h}$ total cycle time to achieve $>98 \%$ densification. Thus almost $90 \%$ reduction in processing time was achieved using the microwave methodology whilst obtaining the similar densification. Also the microwave procedure does not necessitate a separate binder removal step, which is a major processing advantage. A number of further sintering experiments were performed involving multiple saggers (3-4) aligned either vertically or horizontally to increase the through-put. Based on the results on density distribution, temperature uniformity and electrical performance ${ }^{18}$ it was suggested that in practical situations involving standalone microwave heating, a conveyer belt arrangement wherein sample saggers come back-to-back would be a feasible scenario to sinter multilayer varistors without much thermal gradients. However vertical stacking of multiple saggers were found to yield more homogeneous density distribution and less variance in electrical performance during the hybrid sintering of MLVs. Hybrid heating experiments also clearly indicated that the use of microwaves leads to finer microstrucrture, better control over grain boundary phase formation and their distribution and are indeed beneficial to the performance of the varistor devices ${ }^{16,18}$. More than 12000 MLV units can be sintered to high densification ( $>98 \%$ ) using this methodology and the electrical properties were found to be superior to that of the conventionally processed samples ${ }^{18}$.

\section{CONCLUSIONS}

The micrc Figure 3: Electrical characteristics of the microwave sintered ig of a variety of electroceramic $d \epsilon$ nano and commercial varistor samples rapidity and geneıa dppincaumity.

liness, simplicity,

\section{ACKNOWLEDGEMENTS}

The authors thank Littelfuse Ireland Ltd for their valuable support in carrying out this work.

\section{REFERENCES}

1. R.J. Lauf, C.E. Holcombe and C. Hamby, Microwave sintering of multilayer ceramic capacitors, Materials Research Symposium Proceedings, 269, 223-229 (Materials Research Society, 1992).

2. L.M. Levinson, H.A. Comanzo and W.N. Schultz, Microwave sintering of ZnO varistor ceramics, Materials Research Symposium Proceedings, 269, 311-321(Materials Research Society, 1992)

3. B. Vaidhyanathan, R. Raghavendra, and D.K. Agrawal, "Firing of electrodes for the production of passive devices”, European Patent, EP 1100095 (2001). 
4. B. Vaidhyanathan, J. Wang, J.G.P. Binner and R. Raghavendra, The effect of conventional, microwave and hybrid heating on the sintering of ceamics, Proc. of the $9^{\text {th }}$ AMPERE conference on microwave and RF heating, edited by J. Binner, Loughborough, United Kingdom, 31-34 (2003).

5. D.K. Agrawal, R. Raghavendra and B. Vaidhyanathan, Production of Passive Devices, US Patent, 6,399,012 (2002).

6. T.R. Shrout, D.K. Agrawal and B. Vaidhyanathan, Microwave sintering of multilayer dielectrics with base metal electrodes,US Patent, 6,610,241 (2003).

7. J.G.P. Binner and B. Vaidhyanathan, Microwave Sintering of Ceramics: What does it offer?, Key Eng. Mater., 264-268, 725-729 (2004).

8. H.S. Shulman, Microwaves in High-Temperature Processes, Industrial Heating Magazine: The Int. J. Therm. Tech., 43-47 (March 2003).

9. R.F. Schiffman, Commercializing microwave systems: Paths to success or failure, Ceram Tran., 59, 7-14 (1995).

10. N.A. Hassine, J.G.P. Binner and T.E. Cross, Synthesis of Refractory Metal Carbides via Microwave Carbothermal Reduction, Int. J. Refractory Metals and Hard Mat., 13[6], 353-358 (1995).

11. B. Vaidhyanathan and J.G.P. Binner, Microwave Assisted Synthesis of Nanocrystalline YAG, Proc. of the $9^{\text {th }}$ AMPERE conference on microwave and RF heating, edited by Jon Binner, Loughborough, United Kingdom, 273-276 (2003).

12. J.G.P. Binner and B. Vaidhyanathan, Processing of bulk nanostructured ceramics, J. Eur. Ceram. Soc. 28, 1329-1339 (2008).

13. R. Zue, L. Li, Y. Tang, and Z. Gui, Mutual diffusion at heterogeneous interfaces in co-fired composite MLCCs, British Ceram. Trans., 100[1], 38-40 (2001).

14. B. Vaidhyanathan, K. Annapoorani, J.G.P. Binner, and R. Raghavendra, Microwave Sintering of Integrated Passive Devices, Microwave and Radio Frequency Applications, Edited by D. C. Folz, J.H. Booske, D.E. Clark, and J.F. Gerling, 423-428 (2003).

15. W.I. Chen, X.H. Wang, Sintering dense nanocrystalline ceramics without final-stage grain growth, Nature, 404, 168-171 (2000).

16. K. Annapoorani, "Microwave Processing of electroceramic devices”, Ph.D Thesis, Loughborough University, UK (2005).

17. K. Annapoorani, B. Vaidhyanathan, J.G.P. Binner and R. Raghavendra, Microwave Assisted Processing of Nanocrystalline Varistor Devices, J. Euro. Ceram. Soc., To be Submitted (2009).

18. B. Vaidhyanathan, K. Annapoorani, J.G.P. Binner, R. Raghavendra and D.K. Agrawal, Microwave Assisted Large Scale Sintering of Multilayer Varistor Devices, J. Mater. Sci., Submitted (2009).

\footnotetext{
* Author for correspondence: B.Vaidhyanathan@lboro.ac.uk ; PH: +44 1509 223152; FAX: +44 1509 223949

${ }^{* *}$ Nominal voltage (Vnom): This is the voltage measured corresponding to $1 \mathrm{~mA}$ current $\left(\mathrm{V}_{1 \mathrm{~mA}}\right)$ through the varistor.

Clamp ratio $\left(\mathrm{C}_{\mathrm{r}}\right)$ : This parameter gives the ability of the varistor and is expressed by $\mathrm{C}_{\mathrm{r}}=\mathrm{V}_{\mathrm{c}} / \mathrm{V}_{1 \mathrm{~mA}}$ where $\mathrm{Vc}$ is the voltage measured for a given peak current Ic.

Leakage: It is the maximum current (or corresponding voltage) at which the varistor can be operated without getting significantly heated. Beyond this limiting current the joule heating $\left(\mathrm{I}^{2} \mathrm{R}\right)$ of the ceramic becomes dominant and leads to degradation.

Variance: It is the square root of the standard deviation of the Vnom values.
} 